\begin{tabular}{c} 
Volume and Issues Obtainable at Center for Sustainability Research and Consultancy \\
Sustainable Business and Society in Emerging Economies \\
ISSN: $2708-2504$ (E): 2708-2172 \\
Volume 2: No 1, June 2020 \\
CSRᄃ \\
Journal homepage: $\underline{\text { ww.publishing.globalcsrc.org/sbsee }}$ \\
\hline
\end{tabular}

\title{
Effect of Employer Branding Attributes on Talent Retention with mediating Role of Transformational Leadership
}

\section{${ }^{1}$ Muhammad Imran Hanif, ${ }^{2}$ Zain Saeed Qureshi}

${ }^{1}$ Assistant Professor, Institute of Banking and Finance, Bahauddin Zakariya University Multan, Pakistan

${ }^{2}$ MS Scholar (Business Administration), Institute of Banking and Finance, Bahauddin Zakariya

University Multan, Pakistan, zainsaeed12@yahoo.com

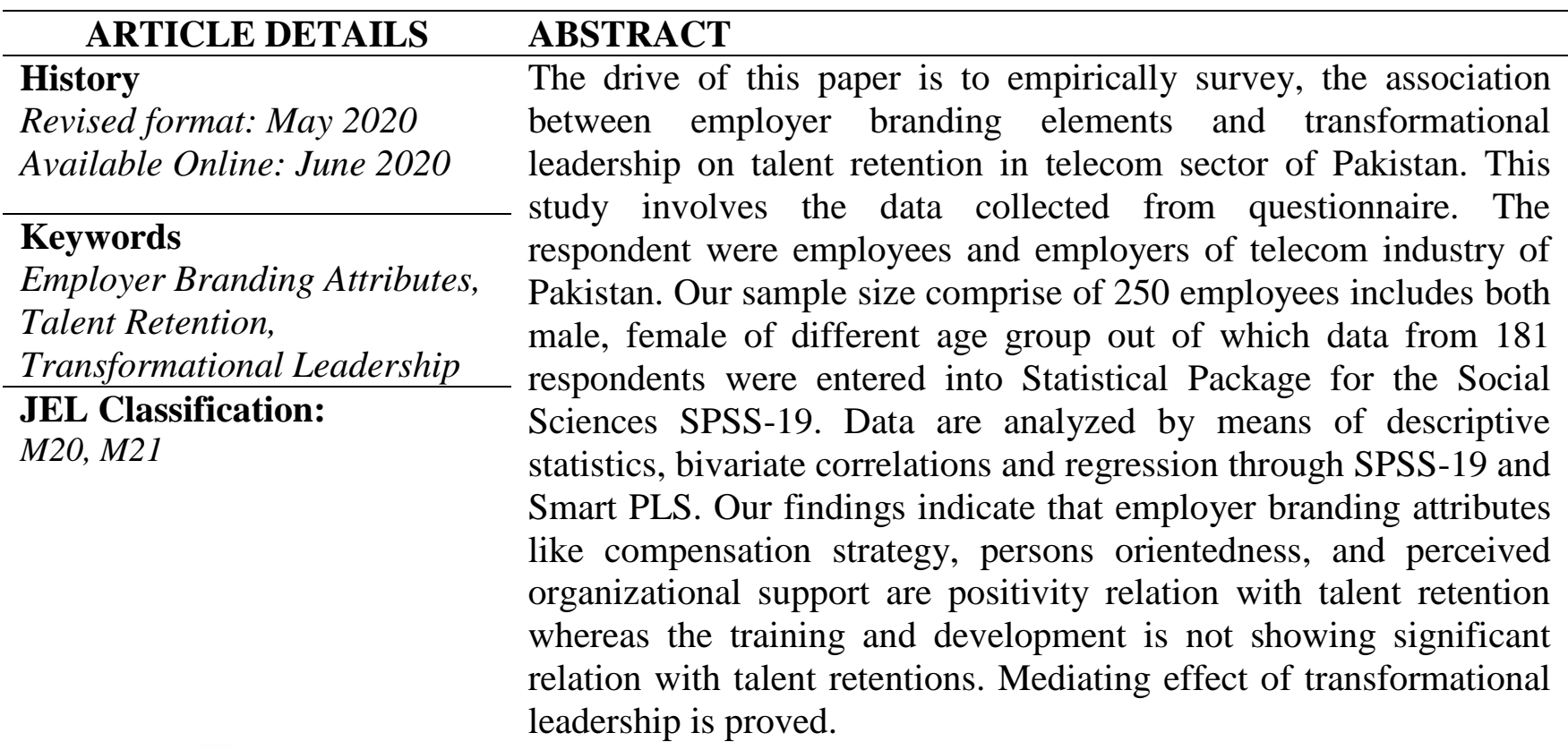

OPEN ACCESS

(C) 2020 The authors, under a Creative Commons Attribution-

NonCommercial 4.0

Corresponding author's email address: zainsaeed12@yahoo.com

Recommended citation: Hanif, M. I., and Qureshi, Z. S. (2020). Effect of Employer Branding Attributes on Talent Retention with mediating Role of Transformational Leadership. Sustainable Business and Society in Emerging Economies, 2(1), 47-54

\section{Introduction}

The aim of this study to explore research conducted by Christopher N. Arasanmi, Aiswarya Krishna, (2019), and checks the effect of employer branding attributes on talent retention and with the mediating role of transformational leadership. Employer Branding Attributes have influenced by Talent Retention this is the explanation that Employer Branding Attributes became an emergent subject matter of research now a days. The goal of this exploration is to study literature and relationship between Employer Branding Attributes and Talent Retention with tallying transformational Leadership as a mediator. The study has decision-making implications for Pakistani organizations. This innovative age of globalization boons many exciting opportunities to international managers, this has increased demand of manager to 
cope up globalization. In era of globalization only those firms succeed and compete which redesign and reshaped their policies and structure with response to dynamic need of markets. Employer branding contains the utilitarian, monetary and mental advantages gave by an organization to its workers. Employeer branding traits are certain for business positive image, and utilized for fascination of potential representatives. (Christopher N, 2019). The adaptability is a most important factor in attaining the key to achieve viable edge. According to Chartered Institute for Personnel and Development (CIPD, (2015). The expression "branding" as applied in human resource management suggests to the arrangement of immaterial traits and characteristics which draw in the potential representatives to offer their administrations to a specific association.

There is rarely any literature available regarding employer branding attributes and talent retention in telecom sector. This Study would shed light on what attributes attract employees and make employer distinctive from other employer in order to keep talent retain and sustain. Prior studied were available on Job Satisfaction and Organizational Commitment. This focuses on Employer Branding attributes along with role of transformational leadership style because they are recognized as influential in the dissemination of best practices.

\section{Literature Review}

\subsection{Employer Branding Attributes}

Employer reputation assumes fundamental task in the advancement of a company's upper hand and manageability. Employer branding advocates for the satisfaction of representatives' goals and desires since workers respond support, favor and support from organizations with obligation and enriched organizational performance. Christopher and Krishna, (2019). In 1996, Ambler and Barrow were pioneer to introduce the term "employer branding" in the field of HRM. Lyons and Marler, (2011) explore that attracting and retaining the talented employees is an emerging issue. Prior researches illustrate that strategies of employer branding effects the competitive advantage of the organization, workers aptitude to recognize corporation standards and member of staff retention (CIPD, 2007). It has been scare exploration work on the linkage concerning employer branding and employee retaining. The paucity of literature appears to reveal the contention that employer branding is now in the emergent stage and a firmness prerequisite for more technologically advanced tactics to entice and retain endowments (Maheshwari et al., 2017). According to Kasekende et al., (2018), assumed that the organization offered as employers branding can be distinguish into three, specifically, remuneration strategy, people's orientedness, leadership and training and developments.

According to Abayomi, (2019) Human Resources Strategy (HRS) needs and Remuneration administration are in line with organization's pursuit, vision, corporate goal and strategy, as well as supporting is strategic in nature especially. Sudhanshu \& Chauhan, (2013) argued that salary is the most crucial factor for employees in the organization. Global Shapers Survey (Annual Survey 2017) conducted by World Economic Forum (WEF), According to the annual Global Shapers through more than 30000 respondents having age under 30 on 180 countries finding were that, $49.3 \%$ consider that salary is the most important criteria in choosing for a job. Training and Development is characterized as the level of career-related bolster got from their chiefs that permits subordinates to control their performance goals, giving performance feedback, helping them the progress profession plans, and provided that training opportunities. As said by Hanif, et al. (2014) training was viewed as basic for maintainable human capacity to be accomplished, results reliably demonstrated that preparation was essential at all the management levels including operational and vital strategic levels. In a report published by US National Economic and Development Office it has been written that the rate of training in high performing organizations is around 8.9 days employee annually whereas those organization having performance is low are 2.8 days employee per annum. Perceived Organizational Support can be looks as an significant organizational resources and it is, consequently, prone to improve subordinates' excitement and vitality levels, for example, work commitment (Park et al., 2018). 
Earlier and contemporary insights on the influence of organizational supports and retention of an employees with an organization such as. Ghosh and Sahaney (2011) revealed that all support either it is organizational support or, career development, interdepartmental support, upper administration support, worker prosperity and work-life security progressively affect talent retention. People Orientedness refers as People who are committed at work find their work energizing and meaningful, and they experience a passionate work-related wellbeing state and enhancing motivation. According to Kasekende et al., (2018) talent endowment retention is fruitful if the employer"s are to construct their corporate brand through motivating workstation pleasurable and work lifespan balance so as to grow their attractiveness.

\subsection{Dependent Variable: Talent Retentions}

Talent retentions is delineate as the exertion through an employer to cling to efficient workers in order to meet expectations' of corporate intentions. Tlaises et al., (2017) described that fascinating, selecting, evolving and retaining talents has now become a top preference among high-ranking leaders which is expressed as managing talents. Korn Ferry Institute, (2017) reported that there is an excruciating "war for talent" being struggled, which is moderately subsequent from an acute shortage supply of talent internationally. A global talent deficiency is heading, and its fiscal impact has been forecasted to extent over US\$8tn by 2030, it is essential for organizations to continue and flourish to retain talent as it always been, and will lifelong process. According to Snejina Michailova, (2018) talented employees prefer career more than a job, when talent is given appropriate career growth chances, they are more ardent to stay loyal with their organization.

\subsection{Mediating Variable: Transformational Leadership Style}

There is an upsurge in overall world leadership conference by the professional senior executive and globally leadership courses, for example at Harvard Business School, the London Business School and the Henley Leadership program. According to Sangeet et al., (2018) it's also observed that diverse styles of leadership are feasible in different cultures. But transformational leadership look like to fit the requirement for an innovative leader, transformational leadership comprises four dimensions: idealized influence, inspirational motivation, intellectual stimulation, and individualized consideration.

\section{Research GAP}

The detailed review of the literature in the previous section reveals that empirical research on talent retention didn't locate a huge connection between initiative advancement practices and talent retention. There is very scarce literature available that deals with impact of Employer Branding Attributes upon Talent Retention in organizations. According to (Christopher et. al, 2019). Further research ought to survey the impact of different factors as manager marking on maintenance. Potential regions incorporate reward and pay, workplaces, manager backing, preparing and improvement as employer branding characteristics.

There is rarely any literature available regarding employer branding attributes and talent retention in telecom sector. This Study would shed light on what attributes attract employees and make employer distinctive from other employer in order to keep talent retain and sustain. Prior studied were available on Job Satisfaction and Organizational Commitment. This focuses on Employer Branding attributes along with role of transformational leadership style because they are recognized as influential in the dissemination of best practices. 


\section{Theoretical Framework}

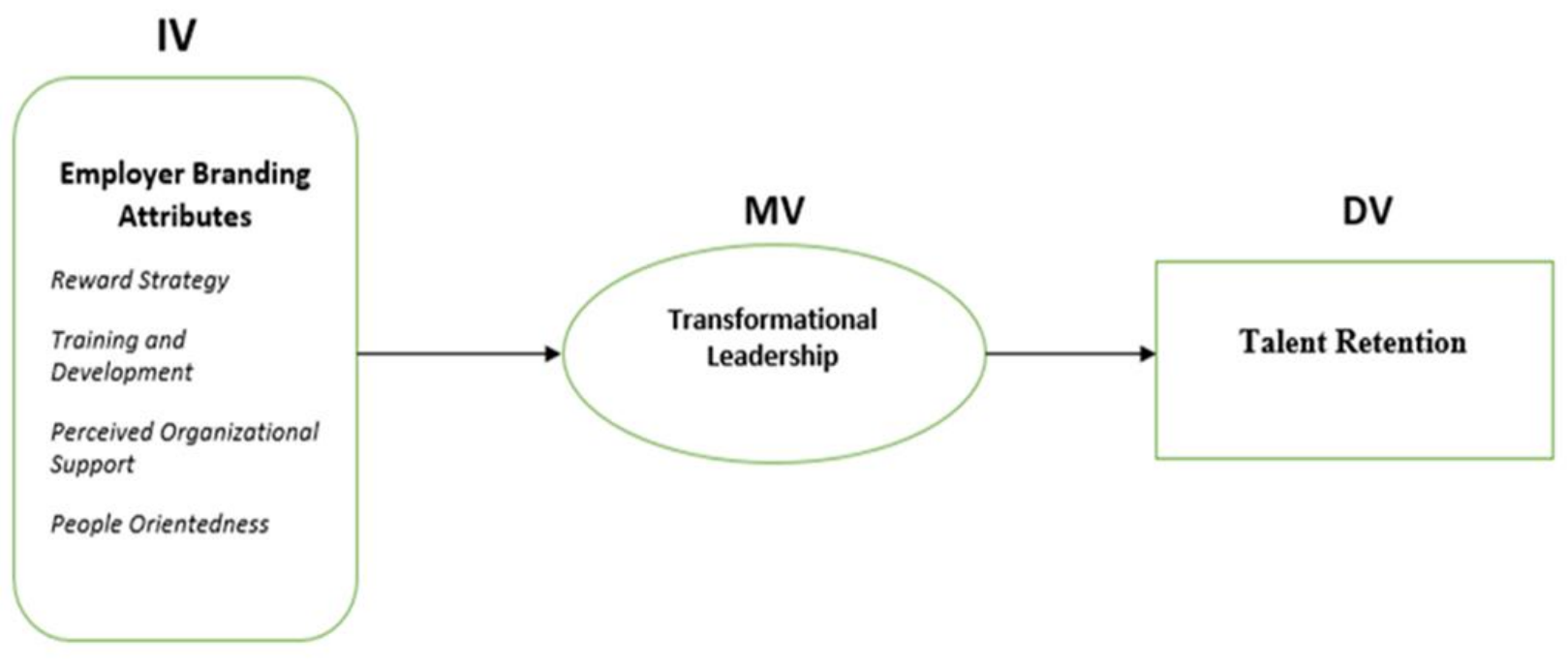

\section{Hypotheses Development}

This subsection develops hypotheses with the aim to fill the research gaps. Main hypotheses are:

H1: Reward strategy is positive related to Talent Retention.

H2 Training and Development is positive related to Talent Retention.

H3 Perceived organization support is positive related to Talent Retention.

H4 People Orientedness is positive related to Talent Retention.

H5 Transformational leadership style may mediate the association between employer's brandings attributes and talent retentions.

\section{Research Methodology}

\subsection{Population and Sample}

The study involves the data collected from the primary sources. The primary source is middle management employees of telecom sector i.e Mobilink, Telenor, Zong, Ufone and PTCL. The questionnaire results illustrated that, there were $72.5 \%$ of male and $27.5 \%$ females. Out of 200 survey questionnaires administered, 181 usable responses were received with a response rate of $90 \%$. Ages of respondents range from less than 25 were $43.5 \%, 32.7 \%$ were aged from 26-30, 31-35 were $40.6 \%$ and $11.6 \%$ respectively and 35 and above were a total of $4.3 \%$. Hence it is seen that the sample was collected without any discrimination. Respondents were from both gender, ageing from less than 26 to 35 and above. There were $27.5 \%$ bachelor, $46.4 \%$ masters, and 23.2\% M.Phil and PhD holders are $2.9 \%$.

\subsection{Data Collection Method $\backslash$ Procedure}

This is quantitative based study a questionnaire was used as instrument.

\subsection{Data Analysis}

Data was arranged enter in SPSS and various tested were perform on data to test validity and reliability.

\subsection{Sampling Technique}

In order to undertake this research a convenient sampling technique was used.

\subsection{Measuring Instrument}

In order to undertaken this research a questionnaire was used as instrument for collecting data. A 1-5 


\section{Likert scale}

( 5 =strongly agree, 4 =agree, 3 =neutral, 2 = disagree, 1 =strongly disagree) used in this study.

Reward strategy; Six measurement items were adapted from (Dileta, 2015). Some of the items are; my organization rewards employees for exemplary work in a variety of ways. Training and development; Four measurement items were adapted from (Broek, 2015). Some of the items are; A job where I can develop into elements of greater responsibility. Perceived organization support; Some of those measurement items of POS were adapted (Christopher et al., 2018). Some of the items are: my organization cares, thinks about my general fulfillment at work; and my organization truly thinks about my prosperity and well-being. People Orientedness: Seven measurement items were adapted from (Broek, 2015). Some of the items are; A job in which I can work occasionally at home, A job in which I can determine the start and end times of my working day itself. Talent Retention; Four items were adapted from Kyndt et al. (2009). One of the items was: f I needed to carry out another responsibility or capacity, I would take a gander at the potential outcomes inside this organization. Transformational leadership; Four measurement items were adapted from (Broek, 2015). Some of the items are; A manager who delegates challenging responsibilities to me, A manager who encourages me to come up with my own initiatives.

\section{Data Analysis and Results}

Reliability Statistics

\begin{tabular}{|l|l|l|}
\hline $\begin{array}{l}\text { Cronbach's } \\
\text { Alpha }\end{array}$ & $\begin{array}{l}\text { Cronbach's } \\
\text { Alpha Based on } \\
\text { Standardized } \\
\text { Items }\end{array}$ & N of Items \\
\hline .879 & .888 & 6 \\
\hline
\end{tabular}

\begin{tabular}{|c|c|c|c|c|c|}
\hline & $\begin{array}{l}\text { Original } \\
\text { Sample }(\mathrm{O})\end{array}$ & Mean (M) & SD & T Statistics & P Values \\
\hline People Orientedness -> Talent Retention & 0.149 & 0.153 & 0.085 & 1.755 & 0.04 \\
\hline People Orientedness -> Transformational Leadership & 0.18 & 0.19 & 0.083 & 2.184 & 0.015 \\
\hline Percieved Org. Support -> Talent Retention & 0.19 & 0.205 & 0.079 & 2.419 & 0.008 \\
\hline Percieved Org. Support -> Transformational Leadership & 0.119 & 0.13 & 0.071 & 1.666 & 0.048 \\
\hline Reward Strategy $->$ Talent Retention & 0.04 & 0.048 & 0.09 & 0.446 & 0.005 \\
\hline Reward Strategy -> Transformational Leadership & 0.28 & 0.283 & 0.062 & 4.529 & 0.000 \\
\hline Training and Development $->$ Talent Retention & 0.193 & 0.208 & 0.13 & 1.478 & 0.07 \\
\hline $\begin{array}{llll}\text { Training and } & \text { Development } & \rightarrow & \text { Transformational } \\
\text { Leadership }\end{array}$ & 0.083 & 0.113 & 0.087 & 0.955 & 0.17 \\
\hline Transformational Leadership -> Talent Retention & 0.166 & 0.159 & 0.077 & 2.159 & 0.015 \\
\hline
\end{tabular}

\section{H1: Reward strategy is positive related to Talent Retention. (Supported)}

The first hypothesis was to check the relationship of Reward strategy and Talent Retention, on the basis results, it is evident that Reward strategy is highly and positively significant with Talent Retention as the significance level is 0.005 .

\section{H2 Training and Development is positive related to Talent Retention. (Not Supported)}

The second hypothesis of the study was to check training and development is significantly related to Talent Retention or not. The statistical results reveal that both variables are not significant with a significance level of 0.07 . This hypothesis is not accepted because the $\mathrm{P}$ value is greater than 0.05 that is less than 0.001

\section{H3 Perceived organization support is positive related to Talent Retention. (Supported)}

The third and most important hypothesis was to test the combined impact of Perceived organization support and Talent Retention. The significance of this hypothesis is 0.000 . The level of significance 
indicates that this hypothesis is approved. If Perceived organization support is employed with talent Retention it will together have a synergetic effect on the enhancement of talent Retention.

\section{H4 People Orientedness is positive related to Talent Retention. (Supported)}

The connection between people's orientedness and talent retentions. The results specified a positive relation and major association between the two. This hypothesis is accepted because the $\mathrm{P}$ value is less than 0.05 that is less than 0.001. The finding for this hypothesis is supported by Asuman et al, (2018), who said that combination of the outcomes ratify that the people orientedness in are positively linked to talent retention.

\begin{tabular}{|l|l|l|l|l|l|}
\hline & $\begin{array}{l}\text { Originals } \\
\text { Sample }\end{array}$ & $\begin{array}{l}\text { Sample } \\
\text { Means }\end{array}$ & $\begin{array}{l}\text { Standards } \\
\text { Deviation }\end{array}$ & $\begin{array}{l}\text { T Statisticss } \\
\text { Salues }\end{array}$ & $\begin{array}{l}\text { P } \\
\text { Value }\end{array}$ \\
\hline Employer Branding -> Talent Retention & 0.437 & 0.438 & 0.105 & 4.176 & 0.000 \\
\hline $\begin{array}{l}\text { Employer Branding -> Transformational } \\
\text { Leadership }\end{array}$ & 0.646 & 0.644 & 0.061 & 10.548 & 0.000 \\
\hline $\begin{array}{l}\text { Transformational Leadership -> Talent } \\
\text { Retention }\end{array}$ & 0.311 & 0.311 & 0.096 & 3.244 & 0.001 \\
\hline
\end{tabular}

\section{H5 Transformational leadership style mediates the association between employer's branding attributes and talent retentions. (Supported)}

The last and most important hypothesis was to test the mediating impact of transformational leadership on employer branding and talent retention. The significance of this hypothesis is 0.000 . The level of significance indicates that this hypothesis is approved. But training and development is not accepted the mediating effect of transformational leadership its $\mathrm{P}$ value is 0.17 which is greater than 0.005 . However, independently they both have different level of significant, where training and development has some extent of significant with talent retention its $\mathrm{P}$ value is 0.07 .

\section{Discussion}

Results of the data analysis in previous section were presented. Mean values for all variables and their associated dimensions were all above 3.00 on a scale from 1.00 to 5.00 except for transformational leadership which was slightly below 3.00. Mean value for independent variable employer branding is 3.8406 which implies that organizations carry out and emphasize employer branding attributes and talent retention also. Mean value for dependent variable talent retention is 3.7971 on a scale from 1.00 to 5.00. As far as mediation is concerned, it has a mean value of 3.6087 which entails that managers perceive business environment to be uncertain and competitive. Through these findings we can infer that all three forms of employer branding attributes are carried out in the sampled firms, however, new talent retention is slightly more emphasized than new offering and branding attributes model in our case. At the point when organization perceive their commitments and show worries for their prosperity and give a positive workplace; at that point representatives are probably going to remain and stay with an organization (Ghosh et al., 2013). Additionally, these findings are consistent with earlier studies. According to this study, make a working environment wheres staff skills are esteemed and remunerated; this results into craving that even then next day would discover them at work station. The examination further finds that representatives in organization would remain be a section in such organizations since they feels that while at certain work environment staff abilities are esteemed and compensated.

\section{Conclusion}

In the country case Telecommunications being a crucial contributor in services sector, remained as a stimulus for rest of the economy. Digitization is the buzzword in literally every segment of the society be it industry, manufacturing, Small \& Medium Enterprises (SMEs), agriculture, health, education or media. Therefore the role of PTA in particular and IT \& Telecom sector in general has become pivotal 
for economic growth and employment generation. Services are one of the best sources to accelerate growth in stagnant or slow growth economies. These facts imply that growth in services is fundamental to the growth of the whole economy. At organizational or business level, innovation is the central driver to competitive advantage and superior performance and is considered an engine of growth. On the other hand, forces of globalization, cut-throat competition, and ground breaking technologies are exerting influence on organizations and economies alike. In the light of gaps identified above, there seemed a void in many areas of employer branding research. This research thesis is an endeavor to bridge the aforesaid gaps in the field and is both timely and needed. This research activity to offers new understandings in the fields of employer branding and talent retention. This shed light on the correlation between main variables employer's branding (IV), talent retentions (DV) and transformational leadership (MV). First, this study finds that employer branding considerably influences talent retention of the telecom sector organizations of Pakistan which was hypothesized to be so. It reinforces the previous findings that employer branding directly impacts talent retention (cite few such studies).

The first hypothesis was to check the relationship of Reward strategy and Talent Retention, on the basis results, it is evident that Reward strategy is highly and positively significant with talent retention as the significance level is 0.005 . The second hypothesis of the study was to check training and development is significantly related to talent retention or not. The statistical results reveal that both variables are not significant with a significance level of 0.07. This hypothesis is not accepted because the $\mathrm{P}$ value is greater than 0.05 that is less than 0.001. The third and most important hypothesis was to test the combined impact of Perceived organization support and Talent Retention. The significance of this hypothesis is 0.000 . The level of significance indicates that this hypothesis is approved. The fourth hypothesis was a relationship between people's orientedness and talents retentions. This results as indicated a significant positive association between the two. So this hypothesis is accepted because the $\mathrm{P}$ value is less than 0.05 that is less than 0.001. The last and most important hypothesis was to test the mediating impact of transformational leadership on employer branding and talent retention. The significance of this hypothesis is 0.000 . The level of significance indicates that this hypothesis is approved.

\section{Implication}

This research study also offers many valued implications for executives in the widespread of sectors and others organizations. Administrators can learn, engage in and choose the finest combination of numerous dimensions of employer branding to synergize talent enactment and gain competitive edge over contenders. They can also learn how different dimensions of employer branding attributes intervene and whether reward strategy and perceive organizational support in the organizational environs play any major role in shaping the optimum unification of various dimensions of employer branding and in overall performance of employees. In this way, this study benefits business and Human resource leaders in their decision making and tactic formulation. Overall, this research study has valuable implications and contributions in the fields of employer branding attributes and talent management alike, apart from some valuable insights for practitioners, managers, service organizations and businesses, policy makers, economist and governments.

\section{Limitations}

This research is not without limitations, these limitations constitute areas for future research First of all, and there is a query of external validity. All the more explicitly, to what degree the consequences of this examination can be summed up outside the telecom area and over other areas. Sample size was not huge enough as there were some budgetary and time limitations which may almost certainly hamper the external validity and generalizability of the after effects of this examination crosswise over whole area and crosswise over creating economies.

\section{Future Research}

This research was carried out on the telecom sector only, hence it would seem interesting to replicate 
this survey on a much more diversified sample of users such as corporates and multinationals, it can focus on entire public sector which may include public financial services, other private financial services, etc. In this study we examined the impact of on these attributes and elements of employer's branding such as compensation and reward strategy, people's orientedness, trainings and developments and perceived organizational supports. So in future other dimension such as Career Advancement, Job Satisfaction, Culture \& Values, Innovation \& Technology, CSR and diversity \& Inclusion should be considered.

\section{References:}

Adeoye, A. O. (2019). COMPENSATION MANAGEMENT AND EMPLOYEES' MOTIVATION IN THE INSURANCE SECTOR: EVIDENCE FROM NIGERIA. Economics and Organization Vol. 16,.

Asuman Matongolo, F. K. (2018). Employer branding and talent retention:perceptions of employees. Industrial and Commercial Training.

Broek, M. t. (2015). FROM EMPLOYER ATTRACTIVENESS TO EMPLOYER BRANDING. MANAGEMENT AND GOVERNANCE.

Christopher N. Arasanmi, A. K. (2019). Employer branding: perceived organisational support and employee retention - the mediating role of. Industrial and Commercial Training.

Ghosh, P. S. (2013). Who stays with you? Factors predicting employees' intention to stay. International Journal of Organizational Analysis, Vol. 21 No. 3, 288-312.

Kamlesh Kumar Maurya, M. A. (2018). Organisational talent management and perceived employer branding. International Journal of Organizational Analysis.

Koustab Ghosh, S. S. (2011). Impact of organizational sociotechnical system on managerial retention. Journal of Modelling in Management.

Marler, B. D. (2011). Got image? Examining organizational image in web recruitment. Journal of Managerial Psychology.

Muhammad Imran Hanif, Y. S. (2014). Role of Talent Management, Diversity Trainings and HRD on Effective Implementation of HR Practices in Telecom Sector in Pakistan. Springer-Verlag Berlin Heidelberg.

Michailova, D. L. (2016). Cultural Intelligence: A Review and New Research Avenues. Park, S. K. (2018). The role of supervisor support on employees' training and job performance: an empirical study. European Journal of Training and Development, Vol. 42 Nos 1/2, 57-74.

Sangeeta Sahu, A. P. (2018). Transformational leadership and turnover: Mediating effects of employee. Leadership \& Organization Development Journal.

Tlaiss, H. A. (2017). Talent retention: evidence from a multinational firm in France. Employee Relations, Emerald Publishing Limited, Vol. 39 No. 4.

Vishwas Maheshwari, P. G. (2017). Exploring HR practitioners' perspective on employer branding and its role in organisational. International Journal of Organizational Analysis.

(2017). Global Shapers Survey. World Economic Forum 